\title{
Educar: ver cores, cinzas e sombras e diferentes maneiras de viver essas diferenças
}

\author{
Maria Cristina Castilho Costa \\ Doutora em Ciências Sociais (Antropologia Social) pela Universidade de São Paulo, onde é \\ Livre-docente em Ciências da Comunicação pela Escola de Comunicações e Artes. Atualmente \\ é professora associada da Universidade de São Paulo, presidente da Comissão de Pesquisa da \\ ECA/USP, coordenadora do Curso de Especialização Lato Sensu Gestão da Comunicação e \\ editora da revista Comunicação \& Educação*. \\ E-mail: criscast@usp.br
}

Resumo: O texto trata da educação - a partir do capítulo $O$ caso do pintor daltônico, publicado no livro Um antropólogo em Marte, do neurologista Oliver Sacks - como um fenômeno amplo e complexo, ao mesmo tempo institucional e não institucional, formal e não formal, que se processa durante toda a vida e que nos faz cada vez mais flexíveis e humanos, capazes de desenvolvermos formas peculiares de enxergarmos 0 mundo, nele nos colocarmos e com ele nos relacionarmos. A comunicação nos oferece recursos para atuarmos nesse processo.

Palavras-chave: Educação, comunicação, humanismo Oliver Sacks, transformação.
Abstract: Based on the chapter The Case of the Colorblind Painter of the book An Anthropologist on Mars by Oliver Sacks, this article talks on education as a wide and complex phenomenon, at the same time institutional and non-institutional, formal and nonformal, that that goes all through life and makes us each time more flexible and human, able to develop peculiar ways of seeing the world, position ourselves inside it and interrelate. Communication offers us resources to perform in this process.

Keywords: Education, tommunication, Oliver Sacks, tumanism, transformation.

Oliver Sacks é um neurologista inglês com forte formação antropológica. Ele publica livros contendo os casos que estudou, tratou ou acompanhou. Em linguagem fácil e bem elaborada, vai tecendo considerações a respeito da percepção humana, da relação entre os sentidos, da forma como o cérebro funciona e responde aos mecanismos da experiência concreta e da linguagem que a expressa. Seus relatos são plenos de sugestão e de releituras, aos olhos da ciência contemporânea e dos grandes debates que interessaram os filósofos desde a Antiguidade. Com aquela capacidade interpretativa própria da cultura judaica, Sacks vai desfazendo os nós que entrelaçam questões envolvendo percepção, cognição, linguagem, imaginação e interação humana. Para termos uma ideia do tipo de estudos médico-antropológicos pelos quais se interessa, basta mencionar $A$ ilha dos daltônicos, que relata uma pesquisa realizada em uma ilha do Pacífico em que a maioria dos habitantes, por

\footnotetext{
"É coordenadora do NPCC - Núcleo de Pesquisa em Comunicação e Censura da USP e do Projeto Temático - Comunicação e Censura - Análise teórica e documental de processos censórios a partir do Arquivo Miroel Silveira. (ECA/USP), com apoio da FAPESP.
} 
manter entre si algum tipo de parentesco e, portanto, de similaridade genética, é daltônica. Ele interessou-se em saber que singularidades comportamentais esse grupo apresentava, uma vez que o padrão médio de normalidade física diferia dos demais habitantes do planeta. Ele intuía, por sua experiência, que deviam ter desenvolvido formas diferentes de ver, nomear, representar e relacionar-se com a realidade.

Como nesse estudo, os muitos livros que escreveu, as diversas palestras que apresentou, inclusive no Brasil, e os inúmeros casos estudados permitem descobrir essa maravilhosa mistura de ciência, filosofia e humanismo, uma transdisciplinaridade regada por uma curiosidade emocionada diante do ser humano. Mas um de seus relatos é ainda o que mais me emociona e o tenho usado reiteradamente em minhas aulas - trata-se de $O$ caso do pintor daltônico, um dos capítulos do livro Um antropólogo em Marte, publicado no Brasil pela Companhia das Letras, em 1995. Neste relato, Sacks conta a história de um pintor que, em 1986, aos 65 anos, em consequência de um acidente de automóvel tornou-se completamente daltônico, impossibilitado, portanto, de distinguir qualquer tipo de cor. Como o autor nos conta, Jonathan I sofre um grande choque por se ver, àquela altura da vida, incapaz de usar as cores, matéria-prima de sua principal atividade como pintor.

As reações que o acidente e o daltonismo desencadeiam são brutais - inicialmente, Jonathan tenta manter a memória das cores e, mesmo não as vendo no ambiente circundante, procura reassumir sua pintura (bastante colorida) produzindo quadros que passaram a ser fruto, principalmente, de sua memória e de gestos aprendidos e fixados em seus hábitos e costumes. Mas o resultado não o agrada nem aos seus amigos e críticos e, aos poucos, ele vai desistindo da empreitada, principalmente ao perceber que sua própria memória ia se esvanecendo e também se tornando incolor. $\mathrm{O}$ momento seguinte foi de desânimo e depressão - ele remodela o ateliê de acordo com sua nova condição, pintando-o de cinza, e nele se enclausura, fugindo de um mundo colorido que ele não mais enxergava, que o desafiava e que lhe resistia. Fechado nesse cenário sem cores, ele via suas reações diante do mundo mudarem - perdeu o apetite por comidas que antes o deliciavam, passando a apreciar azeitonas, iogurtes e café preto. Até mesmo seu cachorro marrom pareceu-lhe sem graça e ele considerou a possibilidade de adquirir um dálmata. Diz Sacks:

A percepção da cor havia sido uma parte essencial não só do sentido visual do Sr. I., mas de seu sentido estético, sua sensibilidade, sua identidade criativa, uma parte essencial de como construía seu mundo - e agora a cor havia desaparecido, não apenas da percepção, mas também da imaginação e da memória ${ }^{1}$.

Dois anos após o acidente, entretanto, Jonathan declarou-se divorciado das cores e começou a desistir de tentar reconstruir sua vida perdida por subterfúgios de comportamento que já não o mobilizavam internamente. Assim, pouco a pouco, aceitando seu daltonismo, começou a explorar suas nova condição perceptiva. Descobriu que a luzes intensas o molestavam e que se sentia muito mais confortável na penumbra. Entendeu também que tinha uma acuidade nova para diferenciar os tons de cinza, com uma precisão muito maior do que a que tinha antes do acidente e do que têm a maior parte dos videntes. Passou a trabalhar à noite e a se dedicar a explorar sua percepção dos cinzas - os quadros que pintou na década subsequente, paisagens em tons de cinza, fizeram grande sucesso. 
Assim, sem deixar de lamentar ter perdido a percepção das cores, o pintor daltônico reconheceu os ganhos havidos com as transformações advindas do acidente de 1986. Jonathan reconhecia que desenvolvera uma aguda visão noturna ${ }^{2}$ que lhe permitia ver formas a uma distância quatro vezes maior do que antes. Adaptar-se a essa nova condição e explorá-la esteticamente foi o passo seguinte que possibilitou ao artista reconstituir seu mundo e sua identidade. A tal ponto que, três anos depois do acidente, quando os médicos lhe ofereceram um tratamento capaz de fazê-lo recobrar a capacidade de ver cores, Jonathan, depois de alguma hesitação, recusou. Seu cérebro, sua afetividade, suas motivação e seu senso estético haviam já se adaptado à nova forma de ver e entender o mundo e de nele se localizar, se orientar e se relacionar.

\section{EDUCAÇÃO - PROCESSO DE TRANSFORMAÇÃO, FLEXIBILIZAÇÃO E DESENVOLVIMENTO HUMANO}

Por que inicio a apresentação deste número da Revista Comunicação $\mathfrak{E}$ Educação por este relato? Porque ele me parece a melhor referência para aquilo que se configura como a educação nos tempos atuais, plenos de mudanças e transformações em nossa maneira de ver e perceber a nós e aos outros. Nem todos nós sofremos acidentes radicais como o que acometeu o pintor Jonathan, mas todos nós, sem exceção, estamos diante de um mundo em mudança que desafia nossas formas tradicionais de sentir, pensar e reagir à vida. E muitos de nós acabamos por desistir de encontrar novas soluções para seus problemas. Diante desse mundo em mudança, a educação parece ser realmente essa capacidade que nos faz flexíveis e capazes de desenvolvermos habilidades novas que nos façam incluídos, participantes, atuantes e produtivos.

Há muito que a educação não se resume mais à instituição escolar, às atividades pedagógicas, à capacidade de obter e gerenciar informações, mas a essa habilidade infinita de, nas mais diferentes circunstâncias, sermos cada vez mais flexíveis, adaptativos e humanos, desenvolvendo e explorando nossas competências e potencialidades nas mais diferentes situações. A educação (ou reeducação) de Jonathan I continuou aos 65 anos, após perdas profundas e presumivelmente irrecuperáveis, num cenário de vida estável e instituído, exigindo dele, antes de tudo, ser aberto ao novo e flexível em suas reações, no corpo, na mente, na emotividade, na percepção estética e na maneira de ver e se colocar no mundo.

Falamos, portanto, de uma educação permanente, institucional e não institucional, formal e não formal, particular e universal, individual e coletiva, voltada para o sentir e para o fazer, para o pensar e para o expressar, que tem como objetivo primordial nos fazermos mais humanos, enxergando a vida de forma mais completa, com suas peculiaridades e nuances.

É para educadores que pensam a educação dessa maneira que a revista Comunicação $\mathcal{E}^{2}$ Educação é pensada e realizada e é para esses educadores que procuramos apresentar experiências e reflexões que mostrem de que maneira a comunicação pode ajudar a desenvolver essa visão ampla e complexa da vida, plena de cores, cinzas e sombras e diferentes formas de processá-las.

Neste número, há muitas reflexões nesse sentido, seja para colocar o leitor diante de conceitos das duas disciplinas - a comunicação e a educação -, seja para apresentar aos interessados os resultados de pesquisas, experiências e análises que buscam 
comunicação \& educação • Ano XVI • número 2 • jul/dez 2011

desvendar esse campo profícuo da comunicação e da educação. São análises que buscam estudar os meios de comunicação como veículos de sociabilidade, inclusão, cidadania e diálogo, atuando em relação a uma educação que envolve transformação, desenvolvimento humano e conscientização. Vamos ver que desafios elas nos colocam.

\section{TEORIA DA COMUNICAÇÃO - INTERDISCIPLINARIDADE E INTERSECÇÕES}

Iniciamos os textos e ensaios nacionais com um artigo de José Marques de Melo sobre o desenvolvimento de estudos interdisciplinares, os quais o autor denomina economia política da comunicação. Com base em sua própria experiência intelectual e acadêmica, mostra como as diversas teorias foram construindo essa interface dos estudos das comunicações.

\section{A ORALIDADE E O TECIDO DA CULTURA}

Walter de Sousa Junior estuda há anos a cultura circense. Sua tese de doutorado teve por objeto o circo-teatro e sua pesquisa de pós-doutoramento pretende resgatar o patrimônio deixado em São Paulo pelo nosso palhaço maior, o Piolim. Nessas pesquisas ele pode avaliar a grande contribuição dos circos para a difusão da produção cultural brasileira, abrindo espaço para o teatro, o cinema, o rádio e, depois, a televisão. No presente artigo procura mostrar como a oralidade se constitui numa linguagem poderosa, capaz de instituir uma forma tão peculiar e efêmera de fazer a arte que é o circo.

\section{EXPERIÊNCIA RADIOFÔNICA EM EDUCAÇÃO A DISTÂNCIA}

Quem pensa em Educação a Distância, pensa em computadores, alta tecnologia e grandes redes de comunicação. Mas Adriano Lopes Gomes e Edivânia Duarte Rodrigues, com seu artigo Os discursos da Rádio Rural de Natal nos anos 1960: um capítulo da relação comunicação/educação no Brasil, procuram mostrar como o rádio pode servir aos objetivos da educação quando quer alcançar quem está longe. E alcançar não apenas para informar, para divulgar, mas para promover cidadania, justiça social e formação política. Disso trata esse artigo.

\section{STREET PAPERS: DANDO VOZ ÀS MINORIAS}

Adriano da Silva Rozendo e Suzana da Silva Rozendo abordam, em seu artigo Street papers: instrumento de interação social, esse instrumento de integração social que tem desempenhado importante função social de dar voz a minorias desfavorecidas socialmente. Criado na passagem do século XIX para o XX, os street papers constituíram importante veículo de integração da população dos moradores de rua 
que, através deles, podiam se fazer ouvir pela sociedade em geral. Financiados por governos, entidades assistenciais e religiosas, os street papers mostram que a educação é um processo que envolve questões políticas, ideológicas e sociais.

\section{AMOR E TELENOVELAS}

A telenovela tem ocupado não só o horário nobre da televisão brasileira há décadas, mas também ultimamente o horário nobre dos estudos acadêmicos, tornando-se um dos temas importantes a serem estudados pelas ciências da comunicação. E dentre esses estudos, uma das preocupações importante é saber de que maneira aquilo que é defendido e veiculado pelas telenovelas interfere na realidade, modificando hábitos, comportamentos e valores. Marcus Tadeu Tavares também está preocupado com o tema e, no artigo Relacionamentos amorosos nas telenovelas: consumo e retrato da sociedade do século XXI, ele analisa os modelos amorosos transmitidos pelo gênero, procurando entendê-los à luz de nossa modernidade líquida.

\section{DENTRO E FORA DA ESCOLA}

Nesse primeiro artigo internacional, María Teresa Quiroz Velasco analisa, em Os estudantes: dentro e fora da escola, a influência que a rede Internet e os meios digitais vêm provocando na maneira como estudantes entendem a educação. Com base em pesquisa realizada na Faculdade de Comunicação da Universidade de Lima, ela mostra que educar envolve, hoje, para os jovens, interesse e entretenimento.

\section{RADIODIFUSÃO E CIDADANIA PARTICIPATIVA}

Juan Díaz Bordenave, em seu artigo A contribuição dos meios públicos e alternativos para a democracia participativa, mostra como a radiodifusão é hoje um elemento importante para a construção de uma sociedade participativa e democrática. Por meio da iniciativa do estado e da organização da sociedade civil, a rádio permite o acompanhamento e a intervenção da sociedade na vida política da sociedade. A radiodifusão desempenha também importante papel na relação que se estabelece hoje entre o local e o global.

\section{GESTÃO E FEIRAS LIVRES}

Juliana Tourrucôo Alves vem nos apresentar o projeto desenvolvido para o Curso de Especialização Lato Sensu Gestão da Comunicação: políticas, educação e cultura (ECA-USP), sobre o Sindicato do Comércio Varejista dos Feirantes do Estado de São Paulo e suas dificuldades de ação política e comunicação planejada. A pesquisa em que o projeto se baseia envolveu estudo histórico e antropológico dessa verdadeira instituição social: as feiras livres de rua que, depois de importante papel social, enfrentam o desafio dos sacolóes e supermercados que se instalaram na cidade. A autora mostra como a comunicação pode ajudá-las nesse embate. 
comunicação \& educação • Ano XVI • número 2 • jul/dez 2011

\section{ENTREVISTANDO UM EDUCOMUNICADOR}

Juliana Winkel Marques dos Santos e Vania de Toledo Piza entrevistam Fernando Rosset, um educomunicador com larga experiência em diferentes instituições educacionais em São Paulo. Para as entrevistadoras, Rosset fala sobre o desenvolvimento da educomunicação e de como ela chega já às iniciativas governamentais e empresariais do terceiro setor.

\section{MUITO MAIS...}

Na seção Crítica, Maria Aparecida Baccega e Rosilene Moraes Alves Marcelino analisam capítulos da telenovela Passione, focalizando nossa atenção na personagem Clotilde Iolanda Souza e Silva (Clô), objetivando mostrar o papel do consumo na atualidade como chave de leitura da sociedade contemporânea.

Além desses trabalhos, análises e reflexões, a revista Comunicação \& Educação traz ainda o depoimento de Francisco Brennand, o escultor, sobre a grandiosa obra que erigiu em Pernambuco, instalando-se numa antiga olaria. Como um museu a céu aberto, a Oficina Brennand é um marco na região e em todo o Brasil.

Apresentamos também neste número Antonia Alves Pereira relatando sua experiência com Educação a Distância no projeto intitulado \#Eadsunday: Educação a Distância em Discussão aos domingos - um estudo de caso de uma experiência bem-sucedida no Twitter, apresentada na Conferência Online de Informática Educativa, entre os dias 7 e 19 de fevereiro de 2011. Em Poesia, Adilson Citelli e Cristine Vargas apresentam A poesia de Cacaso, docente, ensaísta e poeta que se dedicou à música popular brasileira, compondo letras para, entre outros, Edu Lobo, Sueli Costa, Elton Medeiros, Danilo Caymmi, Maurício Tapajós e Sivuca.

Ao final ficam as recomendações bibliográficas e videográficas, além da sempre pertinente proposta de Atividades em Sala de Aula de Ruth Itacarambi.

\section{Educar: ver cores, cinza e sombras}

Com todas essas sugestivas reflexões, esperamos justificar a proposta inicial de nosso texto que defende a ideia de uma educação que vai muito além da informação, da adequação comportamental, da instrução, da disciplina e da alfabetização. Envolve um processo sociopsíquico e cognitivo, complexo e flexível que orienta as transformações individuais e coletivas, em quaisquer circunstâncias e contra todo desafio, em direção ao pleno desenvolvimento da natureza humana. 